\title{
INVESTIGAÇÃO DA COMPACTAÇÃO DO SOLO EM ÁREAS SOB INTEGRAÇÃO LAVOURA- PECUÁRIA E PRESERVAÇÃO PERMANENTE
}

\author{
Milena Avelar Dornelas ${ }^{1}$, Michael Silveira Thebaldi²
}

\section{RESUMO}

Com as diversas atividades desenvolvidas no solo, o mesmo pode sofrer algumas modificações graças à carga adicional e consequente compactação, podendo interferir no seu uso e qualidade, assim, analisar a dinâmica da compactação de solo agrícola explorado em manejo de integração lavoura-pecuária é necessário. O objetivo deste trabalho foi analisar a compactação de solo agrícola, em diferentes situações inerentes do sistema de produção caracterizado como integração lavoura-pecuária e em área de preservação permanente. Para tal, foi montado um experimento em delineamento inteiramente casualizado em esquema fatorial 4 x 2, com três repetições, sendo os tratamentos: atividade realizada no solo (4 situações - A1: ao final do ciclo da cultura do milho; A2: após colheita mecanizada do milho; A3; após pastoreio de gado; A4: área de preservação permanente) e profundidade da camada de solo (2 níveis - C1: $0-0,15 \mathrm{~m}$ e C2: $0,15-0,30 \mathrm{~m}$ ). As amostras foram coletadas em uma propriedade rural, a fim de serem analisadas a densidade do solo, porosidade, umidade volumétrica e resistência à penetração. A atividade de pastagem não causou compactação do solo na área analisada, já que a sua densidade e porosidade foram iguais após a realização das atividades inerentes ao sistema produtivo de integração lavoura-pecuária. Assim, a integração lavoura-pecuária foi uma alternativa para o aproveitamento da área, sem que a mesma seja degradada pela compactação.

Palavras-Chave: resistência do solo à penetração, porosidade do solo, densidade do solo

\section{ABSTRACT \\ SOIL COMPACTION RESEARCH IN AREAS UNDER INTEGRATED CROP-LIVESTOCK SYSTEM AND PERMANENT PRESERVATION}

With the many activities on the soil, it may suffer some changes, due to the additional load and consequent compaction, which may interfere with its use and quality. Thus, the analysis of the agricultural compaction dynamics on soil in croplivestock system management it is necessary. The aim of this paper was to analyze the agricultural soil compaction in different situations inherent to the integrated crop-livestock system, and at a permanent preservation area. To this end, a completely randomized design experiment was mounted, in a factorial scheme 4 x 2 , with three replications, being the treatments: activity performed on soil (4 situations - A1: at the end of the corn crop cycle; A2: after corn mechanical harvesting; A3: after cattle grazing; A4: permanent preservation area) and depth of the soil layer (2 levels - C1: 0-0.15 m and C2: 0.15-0.30 m). Samples for the study were collected from a agricultural area, in order to be analyzed soil bulk density, porosity, volumetric water content and soil penetration resistance. The grazing activity does not cause soil compaction in the analyzed area, since the density and porosity of the soil were equal after performing the activities related to crop-livestock production system. Thus, crop-livestock integration was an alternative to area use, without it being degraded by compaction.

Keywords: soil penetration resistance, soil porosity, soil density

\section{Recebido para publicação em 12/12/2015. Aprovado em 08/05/2016.}

1 - Graduanda em Engenharia Ambiental e Sanitária, Centro Universitário de Formiga - MG, milena990@yahoo.com.br

2 - Eng ${ }^{\circ}$ Agrícola, Professor Doutor do Centro Universitário de Formiga - MG, msthebaldi@uniformg.edu.br 


\section{INTRODUÇÃO}

A grande demanda de alimentos pode dificultar a percepção dos impactos causados ao meio ambiente e ao solo em uso pelo aumento das intensivas atividades agrícolas. Diante disso, diversos estudos vêm sendo realizados a fim de verificar a características físicas e mecânicas dos solos submetidos a estas atividades, a fim de minimizar os possíveis impactos de compactação das máquinas e pisoteio de animais.

De acordo com a diversidade de solos e suas características físicas, químicas, biológicas, mineralógicas e morfológicas, além do relevo, pedregosidade e clima, estes respondem diferentemente em cada caso ao manejo, tráfego de máquinas e pisoteio de animais (REICHERT et al., 2010). Com isso, devido às diversas atividades desenvolvidas no solo, ele pode sofrer modificações graças à carga adicional e consequente compactação, podendo interferir no seu uso e qualidade.

$\mathrm{O}$ termo compactação do solo refere-se à compressão deste, devido a um processo em que há o decréscimo de volume de solos não saturados quando uma determinada pressão externa é aplicada. Durante sua ocorrência, há um aumento de sua densidade, ocasionado, muitas das vezes, pelo manejo inadequado, pelo tráfego de máquinas agrícolas, equipamentos de transporte ou animais (FERREIRA; DIAS JÚNIOR, 2001; LIMA, 2004).

$\mathrm{Na}$ literatura técnica, são recomendados o uso de sistemas de manejo com menor revolvimento possível do solo, para que o acúmulo de resíduos vegetais na superfície possibilite a recuperação das propriedades físicas, anteriormente perdidas em áreas degradas pelo preparo inadequado do solo (MARCOLAN; ANGHINONI, 2006).

Para os solos cultivados, em relação à compactação causada pelas máquinas pesadas e diversos números de passagens durante seu manejo, Goedert, Schermack e Freitas (2002) sugerem práticas para atenuar a deformação do solo causada pelas atividades nele exercidas, dentre elas estão a redução de pressões aplicadas pelas máquinas, a preferência ao cultivo mínimo ou plantio direto, o controle do tráfego, a combinação de operações, utilizando a mesma máquina para minimizar o número de passadas, a preservação do solo coberto com vegetação, a utilização de máquinas com baixa carga por eixo e pneus com elevada área de contato, minimizando assim a pressão exercida sobre o solo.

Com a necessidade de alternativas para o aproveitamento das propriedades, a fim de intensificar o uso da terra, aumentar a sustentabilidade dos sistemas de produção e melhorar a renda, a integração da lavoura com a pecuária se faz presente em diversas regiões do Brasil. O interesse, nesse modelo de exploração, apoia-se nos benefícios que podem ser auferidos pelo sinergismo entre pastagens e culturas anuais, como por exemplo a melhoria das propriedades físicas, químicas e biológicas do solo (VILELA et al., 2011).

Assim, o objetivo deste trabalho foi analisar a compactação do solo agrícola, determinando a resistência à penetração do solo em diferentes situações inerentes do sistema de produção caracterizado como integração lavoura-pecuária e em área de preservação permanente, além de avaliar a densidade do solo, porosidade e umidade volumétrica nas mesmas condições supracitadas.

\section{MATERIAL E MÉTODOS}

As avaliações foram feitas em uma propriedade rural, no Município de Medeiros - MG, com Coordenadas UTM 367703.63m E $7777054.14 \mathrm{~m}$ S e com clima Cwb pela classificação de Köppen (ALVARES et al., 2013), que possui área de 120 ha. As áreas selecionadas para o estudo possuíam dimensões de $7,2 \mathrm{~m}^{2}$, sendo uma caracterizada por integração lavoura-pecuária e outra com vegetação nativa local.

A área estudada de integração lavoura-pecuária possuía uma declividade de aproximadamente $0,5 \%$ e a área de vegetação nativa, caracterizada pela preservação permanente, tem uma declividade de aproximadamente $3,52 \%$. O solo predominante na região é predominante o Cambissolo Háplico $\mathrm{Tb}$ distrófico (Cxbd), tendo composição textural como apresentado no Quadro 1, a partir de amostras representativas da camada de 0-0,30 m, sendo classificado como de textura média segundo classificação de Embrapa (1999). 
Quadro 1. Análise de textura do solo na profundidade de $0-0,30 \mathrm{~m}$ no local do experimento.

\begin{tabular}{|c|c|c|c|c|}
\hline $\begin{array}{c}\text { Areia } \\
\text { Grossa }\end{array}$ & $\begin{array}{c}\text { Areia } \\
\text { Fina }\end{array}$ & $\begin{array}{l}\text { Areia } \\
\text { Total } \\
\mathrm{g} \mathrm{kg}^{-1}\end{array}$ & Silte & Argila \\
\hline $\mathrm{ns}$ & $\mathrm{ns}$ & 360 & 150 & 490 \\
\hline
\end{tabular}

Segundo informações do proprietário, a área passa pela atividade de lavoura desde 2010, caracterizada pelas culturas de milho ou soja na safra verão, plantada nos meses de outubro ou novembro, e pela cultura do feijão na safrinha, plantada nos meses de março ou abril.

A área de integração lavoura-pecuária, de 74 hectares, foi cultivada com milho, colhida de maneira mecanizada e depois recebeu pastejo de gado com aproximadamente 100 novilhas, sendo uma taxa de ocupação de 1,35 unidade animal/ha.

Nas áreas do estudo, foram coletadas amostras indeformadas, nas profundidades de $0-15$ $\mathrm{cm}$ e de $15-30 \mathrm{~cm}$, três por profundidade, por percussão, utilizando anéis volumétricos de dimensões desconhecidas. Assim que as amostras indeformadas foram coletadas, as mesmas foram revertidas com filme de policloreto de vinil (PVC), amorim e uma goma elástica para manter a umidade do solo, até que as análises de umidade gravimétrica fossem realizadas. As amostras deformadas foram obtidas às mesmas profundidades e locais.

A primeira amostragem foi realizada no dia 09/04/2015, com lavoura de milho estabelecida, logo antes da realização da colheita.

Após a coleta das amostras de solo, foi realizado ensaio de resistência à penetração utilizando penetrômetro de impacto tipo Stolf. O equipamento foi golpeado até que este ultrapassasse a profundidade de $30 \mathrm{~cm}$, sendo este o critério de parada do ensaio. Para cada golpe realizado, a profundidade atingida pelo cone foi anotada.

A segunda amostragem nesta área ocorreu no dia 11/04/2015, após a colheita mecanizada do milho. Os pontos selecionados para análise foram impactados pelos rodados da colhedora. O plano amostral seguido foi o mesmo do realizado no dia anterior, tanto para amostras de solo (deformadas e indeformadas) e penetrometria.
Após finalização da colheita do milho, no dia $25 / 04 / 2015$, a fazenda foi ocupada por novilhas de aproximadamente 11 arrobas, permanecendo na área por cinco meses, até o dia 01/10/2015. Com isso, no dia 10/10/2015 foi feita a terceira amostragem de solo e ensaio com penetrômetro de impacto tipo Stolf.

Já a última amostragem foi realizada no 10/10/2015, em uma área de $4 \mathrm{~m}^{2}$, caracterizada reserva permanente, em que, há seis anos, não há contato de máquinas nem pisoteio de animais, sendo que não foi realizada nenhuma intervenção mecânica ao solo após o cercamento. Devido à presença de Brachiaria decumbens no local, foi necessário fazer a sua remoção para realização das amostragens e ensaios com penetrômetro. Para isto, foram utilizados os mesmos procedimentos descritos anteriormente.

Para determinação da umidade gravimétrica, volumétrica e de densidade do solo, foram utilizadas as amostras indeformadas de solo coletadas. Os ensaios foram realizados nos Laboratórios de Ciências da Terra e Microbiologia do Centro Universitário de Formiga - UNIFOR-MG.

Para umidade gravimétrica, as amostras indeformadas foram submetidas, após pesagens ainda úmidas, à secagem em estufa a $105^{\circ} \mathrm{C}$, por 24 horas. Após isto, as amostras foram pesadas novamente, a fim da obtenção de sua massa seca.

Como as amostras indeformadas foram pesadas e secadas com a manta de tecido tipo tule, a goma elástica e o anel volumétrico, depois que as mesmas foram secas esses três elementos foram pesados para descobrir o valor das massas úmidas e secas apenas do solo. Para o cálculo da umidade gravimétrica, foi utilizada a Equação 1 (EMBRAPA, 2011).

$$
\mathrm{U}=\frac{\mathrm{Ma}}{\mathrm{Ms}}
$$

em que,

U é a umidade gravimétrica, em $\mathrm{g} / \mathrm{g}$;

$\mathrm{M}_{\mathrm{a}}$ é a massa de água, em $\mathrm{g}$; e

$\mathrm{M}_{\mathrm{s}}$ é a massa de solo seca do solo seca em estufa, em $\mathrm{g}$. 
Já a densidade do solo pode ser obtida pela Equação 2, sendo:

$$
\rho_{\mathrm{S}}=\frac{\mathrm{Ma}}{\mathrm{V}}
$$

em que,

$\rho_{\mathrm{S}}$ é a densidade do solo, em $\mathrm{g} / \mathrm{cm}^{3}$; e

V é o volume do solo, em $\mathrm{cm}^{3}$.

Para a obtenção da umidade gravimétrica, utilizou-se a Equação 3:

$$
\theta=\mathrm{U} \times \rho_{\mathrm{S}}
$$

em que,

$\theta$ é a umidade volumétrica, em $\mathrm{cm}^{3} / \mathrm{cm}^{3}$.

Para determinação da densidade de partículas do solo, os solos provenientes das amostras indeformadas foram destorroados em almofariz com o auxílio de pistilo. Este procedimento foi feito separadamente em amostras coletadas nas profundidades de $0-15 \mathrm{~cm}$ e de $15-30 \mathrm{~cm}$.

Com o fim do processo de destorroamento, o solo foi passado em peneira com malha de $2 \mathrm{~mm}$ para se obter a terra fina. Logo após, seis balões volumétricos de $50 \mathrm{ml}$, previamente pesados, foram preenchidos com terra fina das diferentes profundidades de coleta e pesados novamente para obtenção da massa apenas do solo. Com o uso de bureta graduada de $50 \mathrm{ml}$ e álcool absoluto, os balões foram preenchidos até sua marcação de volume total. A diferença entre o volume total do balão e o volume consumido de álcool para seu total preenchimento caracterizou o volume ocupado pelas partículas de solo (EMBRAPA, 2011).

Assim, as densidades de partícula das amostras foram obtidas com o uso da Equação 4.

$$
\rho_{\mathrm{p}}=\frac{\mathrm{Ms}}{\mathrm{Vs}}
$$

em que,

$\rho_{\mathrm{P}}$ é densidade de partículas do solo, em $\mathrm{g} / \mathrm{cm}^{3}$; e

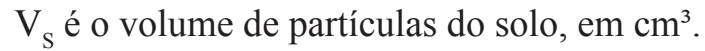

Com isso, a porosidade do solo foi obtida pela Equação 5.

$$
P=1-\frac{\rho s}{\rho p}
$$

Para o cálculo da resistência à penetração, foi utilizado a planilha eletrônica desenvolvida por Stolf et al. (2014), sendo possível a entrada de dados que convertem o número de impactos em resistência do solo à penetração (Equação 6). $\mathrm{Na}$ planilha eletrônica, são utilizadas algumas unidades de conversão de impactos para gerar os gráficos da penetração, sendo a unidade prática obtida pela Equação 6, considerando a aceleração da gravidade igual a $10 \mathrm{~m} / \mathrm{s}^{2}$.

$$
\mathrm{R}=0,1 \times\left[5,6+6,89 \times\left(10 \times \frac{\mathrm{NI}}{\mathrm{P}}\right)\right]
$$

em que,

$\mathrm{R}=$ resistência de solo à penetração $(\mathrm{MPa})$;

$\mathrm{NI}=$ número de impactos; e

$\mathrm{P}=$ penetração $(\mathrm{cm})$.

Os valores obtidos de resistência à penetração, umidade volumétrica, densidade do solo e porosidade, foram analisados em um delineamento inteiramente casualizado (DIC) em esquema fatorial, 4 × 2, com três repetições, sendo os tratamentos: atividade realizada no solo (4 situações - A1: ao final do ciclo da cultura do milho; A2: após colheita mecanizada do milho; A3 - após pastoreio de gado; A4 - área de preservação permanente) e profundidade da camada de solo (2 níveis - $\mathrm{C} 1: 0-15 \mathrm{~cm}$ e $\mathrm{C} 2: 15-30 \mathrm{~cm}$ ).

Os resultados foram comparados pelo teste de F a 5\% de significância estatística. Nas análises em que o teste de $\mathrm{F}$ foi significativo, procedeu-se teste de Scott-Knott, também com 5\% de probabilidade, para comparação de médias. As análises estatísticas foram realizadas com o software Assistat em sua versão 7.7 (SILVA; AZEVEDO, 2006).

\section{RESULTADOS E DISCUSSÃO}

O resumo da ANOVA nas avaliações de densidade do solo, porosidade e resistência à penetração, submetidas atividades no solo e nas duas profundidades avaliadas, é apresentado no Quadro 2.

\section{REVENG}


Quadro 2. Quadro resumo da ANOVA das variáveis densidade do solo, porosidade, umidade e resistência à penetração.

\begin{tabular}{cccccc}
\hline \multirow{2}{*}{ FV } & GL & \multicolumn{4}{c}{ Quadrado Médio } \\
\cline { 3 - 6 } & & ds & P & $\theta$ & RP \\
\hline Atividade (A) & 3 & $0,00683^{\text {ns }}$ & $25,67073^{\text {ns }}$ & $0,01204^{* *}$ & $3,11176^{* *}$ \\
Camada (C) & 1 & $0,00104^{\text {ns }}$ & $2,25415^{\text {ns }}$ & $0,00488^{\text {ns }}$ & $7,37224^{* *}$ \\
A x C & 3 & $0,00010^{\text {ns }}$ & $0,21889^{\text {ns }}$ & $0,00323^{\text {ns }}$ & $1,01891^{*}$ \\
Resíduo & 16 & 0,00664 & $1,419,727$ & 0,00110 & 0,29246 \\
Total & 23 & & & & \\
cv (\%) & & 7,22 & 7,92 & 9,72 & 18,50 \\
\hline
\end{tabular}

Em que: ** significativo ao nível de $1 \%$ de probabilidade $(\mathrm{p}<0,01),{ }^{*}$ significativo ao nível de $5 \%$ de probabilidade $(0,01 \leq \mathrm{p}<$ $0,05)$, ns: não significativo $(\mathrm{p} \geq 0,05)$, ds: densidade do dolo, $\mathrm{P}$ : porosidade, RP: resistência à penetração, $\theta$ - umidade volumétrica do solo.

A densidade do solo e porosidade não foram influenciados pelas diferentes atividades no solo, pelas duas profundidades de camada e bem como pela interação destes dois fatores. $\mathrm{Na}$ avaliação da umidade volumétrica, apenas o efeito simples da atividade no solo foi significativo pelo teste F. Já para resistência à penetração, foram detectadas diferenças significativas para ambos os efeitos simples (à $1 \%$ de probabilidade estatística pelo teste F), bem como para a interação, à $5 \%$ de probabilidade pelo teste $\mathrm{F}$.

Mesmo sem diferença estatística, as médias de densidade solo em função das atividades realizadas e nas camadas de 0 a 15 e 15 a 30 cm, são mostradas no Quadro 3.

Quadro3.Densidade do solo, em g/ $\mathrm{cm}^{3}$, encontrada em função da atividade nele realizada e profundidade da camada de solo.

\begin{tabular}{ccc}
\hline \multirow{2}{*}{ Atividade no solo } & \multicolumn{2}{c}{ Profundidade da Camada } \\
\cline { 2 - 3 } A1 & \multicolumn{1}{c}{$\mathrm{C} 1$} & $1,1289 \mathrm{aA}$ \\
A2 & $1,1346 \mathrm{aA}$ & $1,1233 \mathrm{aA}$ \\
A3 & $1,1776 \mathrm{aA}$ & $1,1557 \mathrm{aA}$ \\
A4 & $1,0879 \mathrm{aA}$ & $1,0811 \mathrm{aA}$ \\
\hline
\end{tabular}

Valores seguidos por mesma letra minúscula na vertical e maiúscula na horizontal, não diferem entre si pelo teste de Scott-Knott à 5\% de probabilidade.
As densidades do solo obtidas foram estatisticamente iguais em todos os tratamentos, não havendo assim influência do manejo e profundidade do solo sobre a mesma. Mesmo assim, numericamente, os valores variaram de $1,0811 \mathrm{~g} /$ $\mathrm{cm}^{3}$ na área de preservação em profundidade de $0,15-0,30 \mathrm{~m}$ à $1,1776 \mathrm{~g} / \mathrm{cm}^{3}$ após o pastoreio de gado na camada de $0-0,15 \mathrm{~m}$. Já as médias de porosidade do solo, em função dos diferentes tratamentos, podem ser vistos no Quadro 4.

Quadro 4. Porosidade do solo, em porcentagem, em função da atividade nele realizada e profundidade da camada.

\begin{tabular}{ccc}
\hline \multirow{2}{*}{ Atividade no solo } & \multicolumn{2}{c}{ Profundidade da Camada } \\
\cline { 2 - 3 } & C1 & C2 \\
\hline A1 & $47,0224 \mathrm{aA}$ & $47,2890 \mathrm{aA}$ \\
A2 & $46,6957 \mathrm{aA}$ & $47,5473 \mathrm{aA}$ \\
A3 & $45,0131 \mathrm{aA}$ & $46,0370 \mathrm{aA}$ \\
A4 & $50,2928 \mathrm{aA}$ & $50,6024 \mathrm{aA}$ \\
\hline
\end{tabular}

Valores seguidos por mesma letra minúscula na vertical e maiúscula na horizontal, não diferem entre si pelo teste de Scott-Knott à $5 \%$ de probabilidade.

Avaliando a densidade e a porosidade total do solo, é possível observar que com as diferentes atividades submetidas a ele e profundidades 
da camada do solo não houve diferenças entre os valores observados, assim pode-se inferir que, para as condições avaliadas, o sistema de integração lavoura-pecuária preservou estas duas características do solo.

Para Spera et al. (2009), quando há redução da porosidade total da camada superficial em relação à camada mais profunda, indica que ocorreu uma degradação da estrutura do solo. Tal fato não foi observado neste estudo, já que foram encontrados os mesmos valores de porosidade nas camadas superior e inferior. Os mesmos autores afirmam ainda que mesmo com as alterações sofridas devido ao sistema de integração lavoura-pecuária, essas alterações não atingem níveis que indicam degradação do solo.

Albuquerque, Sangoi e Ender (2001) e Bertol et al. (2004) observaram que a densidade do solo é maior na camada superficial e decresce nas maiores profundidades, quando em plantio direto e a porosidade total comporta-se de modo inverso.

Em relação à umidade do solo, os valores obtidos foram significativos quanto a atividade nele desenvolvida. Já para os demais fatores não houve uma significância estatística. Assim, o Quadro 5 mostra os valores de umidade volumétrica em função da atividade realizada no solo.

Quadro 5. Umidade volumétrica do solo em função da atividade nele realizada.

\begin{tabular}{cc}
\hline Atividade no solo & $\theta\left(\mathrm{cm}^{3} \mathrm{H}_{2} \mathrm{O} / \mathrm{cm}^{3}\right.$ solo $)$ \\
\hline A1 & $0,37852 \mathrm{a}$ \\
A2 & $0,36846 \mathrm{a}$ \\
A3 & $0,27897 \mathrm{~b}$ \\
A4 & $0,33798 \mathrm{a}$
\end{tabular}

Valores seguidos por mesma letra na vertical, não diferem entre si pelo teste de Scott-Knott à 5\% de probabilidade.

Ao observar o Quadro 4, tem-se que a umidade volumétrica na área após a atividade de pastagem (A3) se difere dos demais tipos de atividades realizadas, sendo menor. Para as três outras atividades (A1, A2 e A4), as umidades no momento da coleta de amostras e ensaio de resistência à penetração era o mesmo.

Mesmo não sendo identificadas diferenças significativas na interação entre as fontes de variação, na avaliação da umidade volumétrica do solo, as médias desta são apresentadas no Quadro 6.

Quadro 6. Umidade volumétrica do solo encontrada em função da atividade nele realizada e profundidade da camada.

\begin{tabular}{ccc}
\hline \multirow{2}{*}{$\begin{array}{c}\text { Atividade no } \\
\text { solo }\end{array}$} & \multicolumn{2}{c}{ Profundidade da Camada } \\
\cline { 2 - 3 } A1 & $0,3872 \mathrm{aA}$ & $0,3699 \mathrm{aA}$ \\
A2 & $0,3630 \mathrm{aA}$ & $0,3740 \mathrm{aA}$ \\
A3 & $0,2329 \mathrm{aA}$ & $0,3251 \mathrm{aA}$ \\
A4 & $0,3239 \mathrm{aA}$ & $0,3521 \mathrm{aA}$ \\
\hline
\end{tabular}

Valores seguidos por mesma letra minúscula na vertical e maiúscula na horizontal, não diferem entre si pelo teste de Scott-Knott à $5 \%$ de probabilidade.

Mesmo sem ter sido identificada diferença significativa da umidade volumétrica do solo submetida à interação entre fontes de variação, nota-se uma inferioridade considerável para o valor obtido após o pastejo de gado, na camada superior do solo. Leão et al. (2004), discutindo sobre a qualidade física do solo em áreas de pastejo bovino, afirmam que o grau de compactação causado pelo pisoteio bovino é influenciado pela textura e umidade do solo, sistema de pastejo e altura de manejo da pastagem, porém o efeito deste sobre os atributos físicos são mais pronunciados nas camadas superficiais do solo (TORRES et al., 2012), não sendo, portanto, a umidade volumétrica fator influenciador neste estudo

Como foi obtida significância para o efeito simples "Atividade realizada no solo" sobre a resistência à penetração, no Quadro 7 é apresentada as médias deste em cada um dos níveis avaliados.

Quadro 7. Resistência à penetração do solo em função da atividade nele realizada.

\begin{tabular}{cc}
\hline Atividade no solo & RP (MPa) \\
\hline A1 & $2,39409 \mathrm{c}$ \\
A2 & $2,31735 \mathrm{c}$ \\
A3 & $3,85420 \mathrm{a}$ \\
A4 & $3,12842 \mathrm{~b}$
\end{tabular}

Valores seguidos por mesma letra na vertical, não diferem entre si pelo teste de Scott-Knott à 5\% de probabilidade. 
Na lavoura de milho (A1) e após a colheita mecanizada (A2) do mesmo, não houve diferenças da resistência à penetração, mostrando assim que o uso de colhedoras não promoveu aumento desta variável. Já após atividade de pastejo na área (A3), obteve-se a maior RP média encontrada no estudo, com um valor de 3,85420 MPa, seguida da área de preservação (A4), com resistência à penetração de 3,12842 MPa.

A área de preservação pode possuir maior resistência à penetração que as áreas cultivadas, por ter se mantido intacta após ter sido intensamente impactada durante anos, conservando, portanto, características mecânicas previamente obtidas. Outro fator a ser observado é o preparo anual da área cultivada com milho, que revolve a camada agricultável anualmente.

Os maiores valores de Resistência à Penetração em A3 podem ser explicados pela menor umidade do solo. Quanto menor a umidade do solo, maior a resistência deste à penetração (REICHERT et al., 2010).

A análise do efeito apenas da profundidade sobre os valores de RP são mostrados no Quadro 8.

Quadro 8. Resistência à penetração $(\mathrm{MPa})$ em função da profundidade da camada avaliada.

\begin{tabular}{cc}
\hline Tratamento & RP $(\mathrm{MPa})$ \\
\hline $\mathrm{C} 1$ & $3,47775 \mathrm{a}$ \\
$\mathrm{C} 2$ & $2,36928 \mathrm{~b}$ \\
\hline
\end{tabular}

Valores seguidos por mesma letra na vertical, não diferem entre si pelo teste de Scott-Knott à 5\% de probabilidade.

A RP na camada de $0-15 \mathrm{~cm}$ (P1) foi superior à avaliada na camada inferior, $\mathrm{P} 2$, entre $15-30 \mathrm{~cm}$. A camada superficial do solo fica mais exposta à compactação causada por sobrecargas sobre o solo, seja o tráfego de máquinas, ou mesmo pisoteio de animais, porém estes não são os únicos fatores que influem em incrementos na Resistência à Penetração.

A resistência à penetração, em função da interação entre atividade realizada no solo e a profundidade das camadas podem ser avaliadas com a visualização do Quadro 9.
Quadro 9. Resistência à penetração, em $\mathrm{MPa}$, do solo encontrada em função da atividade nele realizada e profundidade da camada.

\begin{tabular}{ccc}
\hline \multirow{2}{*}{ Atividade no solo } & \multicolumn{2}{c}{ Profundidade da Camada } \\
\cline { 2 - 3 } & $\mathrm{C} 1$ & $\mathrm{C} 2$ \\
\hline A1 & $2,8348 \mathrm{bA}$ & $1,9534 \mathrm{aA}$ \\
A2 & $2,5188 \mathrm{bA}$ & $2,1159 \mathrm{aA}$ \\
A3 & $5,0045 \mathrm{aA}$ & $2,7039 \mathrm{aB}$ \\
A4 & $3,5529 \mathrm{bA}$ & $2,7039 \mathrm{aA}$ \\
\hline
\end{tabular}

Valores seguidos por mesma letra minúscula na vertical e maiúscula na horizontal, não diferem entre si pelo teste de Scott-Knott à $5 \%$ de probabilidade.

A maior resistência à penetração foi obtida após pastoreio de gado e na camada de $0-15 \mathrm{~cm}$. Para esta mesma atividade, a RP na camada mais profunda a esta foi menor. Porém, como mostrado anteriormente, a umidade do solo nesta condição, mesmo não tendo sido estatisticamente inferior às demais, foi consideravelmente menor, condição que infere em maior RP. Já nas outras interações entre fatores, a resistência à penetração não se diferenciou significativamente pelo teste de ScottKnott à $5 \%$ de probabilidade.

Há de salientar que o valor de resistência à penetração igual ou superior à $2 \mathrm{MPa}$ tem sido utilizado como crítico para o desenvolvimento das plantas (REICHERT; SUZUKI; REINERT, 2007) e também para definir o limite inferior de água no solo na quantificação do intervalo hídrico ótimo (SILVA et al., 1994).

Os perfis de resistência à penetração do solo, em função das diferentes atividades realizadas no solo, numa camada de 0 a $0,30 \mathrm{~m}$, são mostradas na Figura 1.

Os dados mostrados na Figura, corroboram com os apresentados no Quadro 9, podendo-se observar uma maior resistência à penetração na condição de pastagem, à $7,5 \mathrm{~cm}$, porém essa maior resistência pode ser explicada pela umidade do solo no momento do ensaio.

Para Balbinot Junior et al. (2009), a principal preocupação com a integração lavoura-pecuária é sobre a possibilidade de compactação do solo 


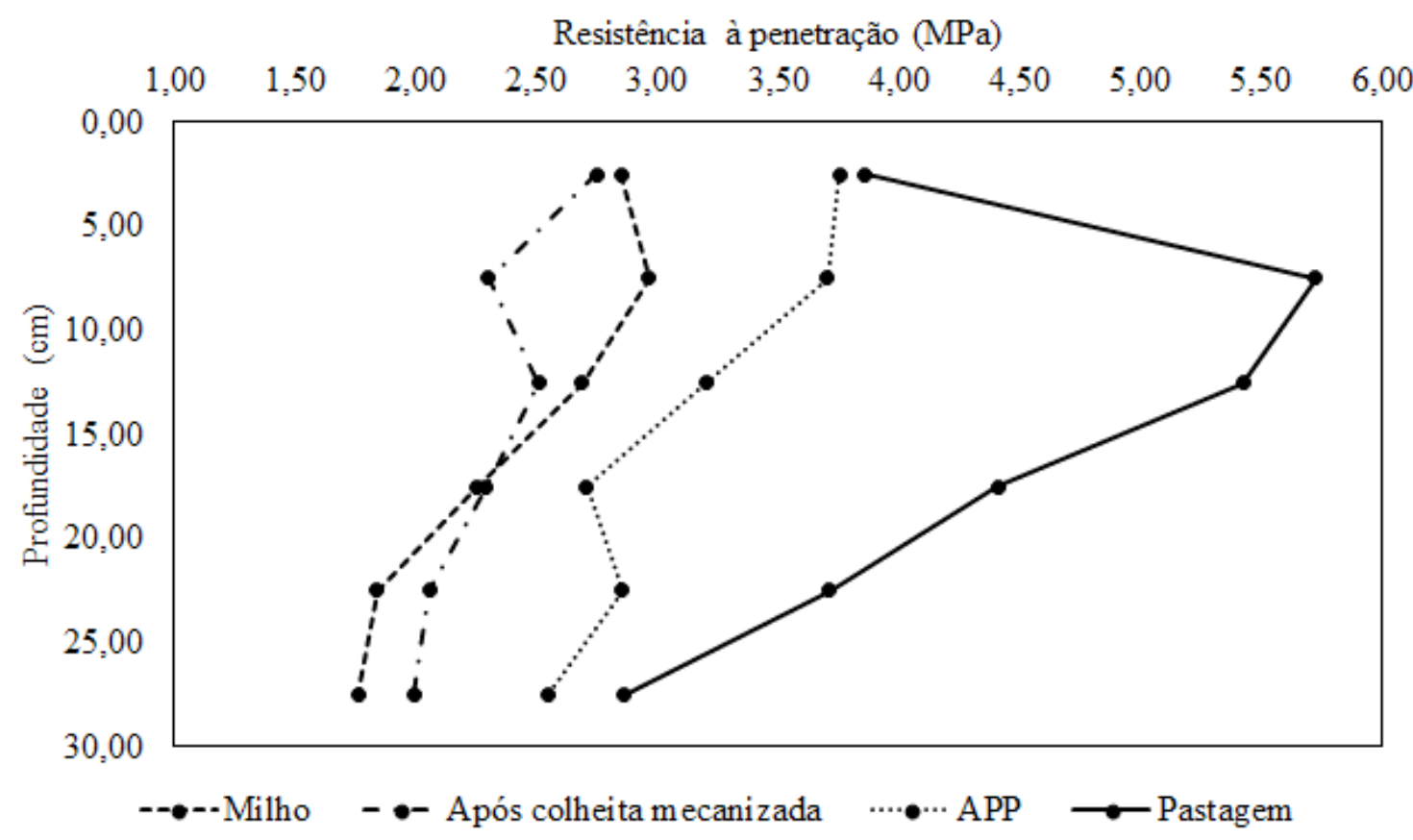

Figura 1. Perfis de resistência à penetração do solo em função da atividade nele realizada, na camada de 0 a $0,30 \mathrm{~m}$.

provocada pelo pisoteio de animais. Contudo, não foram observados neste estudo efeitos significativos sobre a densidade do solo e sua porosidade.

Em sistemas de integração lavoura-pecuária, as alterações de densidade e porosidade do solo (TREIN; COGO; LEVIEN, 1991; SPERA et al. 2004, 2009; FLORES et al. 2007) possuem um grau mínimo de magnitude e não inibem o crescimento das raízes das plantas cultivadas, sendo que a pressão aplicada pelas patas do gado não é superior à resistência à penetração do solo (DIAS JÚNIOR; PIERCE, 1996), não impedindo que o solo recupere sua estrutura.

\section{CONCLUSÕES}

- A integração lavoura-pecuária foi uma alternativa para o aproveitamento da área, sem que a mesma seja degradada pela compactação.

- A atividade de pastagem não causou compactação do solo na área analisada, por não ter sido identificadas modificações de densidade e porosidade do solo, após a realização das atividades inerentes ao sistema produtivo de integração lavoura-pecuária.

\section{REFERÊNCIAS BIBLIOGRÁFICAS}

ALBUQUERQUE, J.A.; SANGOI, L.; ENDER, M. Efeitos da integração lavoura-pecuária nas propriedades físicas do solo e características da cultura do milho. Revista Brasileira de Ciência do Solo, Viçosa, v.25, p.717-723, 2001.

ALVARES, C.A.; STAPE, J.L.; SENTELHAS, P.C.; GONÇALVES, J.L.M.; SPAROVEK, G. Köppen's climate classification map for Brazil. Meteorologische Zeitschrift, v.22, n.6, p.711-728, 2013.

BALBINOT JUNIOR, A.A.; MORAES, A.; VEIGA, M.; PELISSARI, A.; DIECKOW, J. Integração lavoura-pecuária: intensificação de uso de áreas agrícolas. Ciência Rural, Santa Maria, v.39, n.6, 2009.

BERTOL，I.; ALBUQUERQUE, J.A.; LEITE, D.; AMARAL, A.J.; ZOLDAN JUNIOR, W.A. Propriedades físicas do solo sob preparo convencional e semeadura direta em rotação e sucessão de culturas, comparadas às do campo nativo. Revista Brasileira de Ciência do Solo, Viçosa, v.28, n.1, p.155-163, 2004. 
DIAS JUNIOR, M.S.; PIERCE, F.J. O processo de compactação do solo e sua modelagem. Revista Brasileira de Ciência do Solo, Campinas, v.20, p.175-182, 1996

DONAGEMA, G.K.; CAMPOS, D.V.B.; CALDERANO, S.B.; TEIXEIRA, W.G.; VIANA, J.H.M. Manual de métodos de análise de solos. Rio de Janeiro: Embrapa Solos, 2011. 230p.

\section{EMBRAPA. Sistema Brasileiro de Classificação} de Solos. Centro Nacional de Pesquisa de Solos. Ministério da Agricultura e do Abastecimento. p.412. Brasília-DF, 1999

FERREIRA, M.M; DIAS JÚNIOR, M.S. Física do solo. Lavras: Editora UFLA/FAEPE. 2001, 117p.

Flores, J.P.C.; Anghinoni, I.; Cassol, L.C.; Carvalho, P.C.F.; Leite, J.G.D.B.; Fraga, T.I. Atributos físicos do solo e rendimento de soja em sistema plantio direto em integração lavoura-pecuária com diferentes pressões de pastejo. Revista Brasileira de Ciência do Solo, Viçosa, v.31, n.4, p.771-780, 2007.

GOEDERT, W.J.; SCHERMACK, M.J.; FREITAS, F.C. Estado de compactação do solo em áreas cultivadas no sistema de plantio direto. Pesquisa Agropecuária Brasileira, Brasília, v.37, n.2, p.223-227, 2002.

LEÃO, T.P.; SILVA, A.P.; MACEDO, M.C.M.; IMHOFF, S.; EUCLIDES, V.P.B. Intervalo hídrico ótimo na avaliação de sistemas de pastejo continuo e rotacionado. Revista Brasileira de Ciência do Solo, Campinas, v.28, p.415-423, 2004.

LIMA, C.L.R. Compressibilidade de solos versus intensidade de tráfego em um pomar de laranja e pisoteio animal em pastagem irrigada. 2004. 70p. Tese (Doutorado em Agronomia) Departamento de Solos e Nutrição de Plantas, Escola Superior de Agricultura "Luiz de Queiroz", Universidade de São Paulo, Piracicaba, SP.

MARCOLAN, A.L.; ANGHINONI, I. Atributos de um Argissolo e rendimento de culturas de acordo com o revolvimento do solo em plantio direto. Revista Brasileira de Ciência do Solo, Viçosa, v.30, n.1, p.163-170, 2006.

REICHERT, J.M.; SUZUKI, L.E.A.S.; REINERT, D.J. Compactação do solo em sistemas agropecuários e florestais: identificação, efeitos, limites críticos e mitigação. In: CERETTA, C.A.; SILVA, L.S.; REICHERT, J.M. Tópicos em Ciência do Solo. Viçosa: SBCS, p.49-134, 2007.

REICHERT, J.M.; REINERT, D.J.; SUZUKI, L.E. A.S.; HORN, R. Mecânica do solo. In: LIER, Q.J.V. Física do solo. Viçosa: Sociedade Brasileira de Ciência do Solo, 2010. 298p.

STOLF, R.; MURAKAMI, J.H.; BRUGNARO, C.; SILVA, L.G.; SILVA, L.C.F.; MARGARIDO. L.A.C. Penetrômetro de impacto Stolf- Programa computacional de dados em Excel-VBA. Revista Brasileira de Ciência do Solo, Viçosa, v.38, n.3, p.774-782, 2014.

SILVA, A.P.; KAY, B.D.; PERFECT, E. Characterization of the least limiting water range of soils. Soil Science Society of America Journal, Madison, v.58, n.6, p.1775-1781, 1994.

SILVA, F.A.S.; AZEVEDO, C.A.V.A new version of the Assistat-Statistical Assistance Software. In: World Congress on Computers in Agriculture, 4., Orlando: Anais... Orlando: American Society of Agricultural and Biological Engineers, 2006. p.393-396.

SPERA, S.T, SANTOS, H.P. ; TOMM, G.O. ; FONTANELI,R.S. Avaliação de alguns atributos físicos de solo em sistemas de produção de grãos, envolvendo pastagens sob plantio direto. Revista Científica Rural, v.9, p.23-31, 2004.

SPERA, S.T.; SANTOS, H.P.; FONTANELI, R.S.; TOMM, G.O. Integração lavoura e pecuária e os atributos físicos de solo manejado sob sistema de plantio direto. Revista Brasileira de Ciência do Solo, Viçosa, v.33, n.1, p.129-136, 2009.

TORRES，J.L.R; RODRIGUES JUNIOR, D.J.; 
SENE, G.A.; JAIME, D.G.; VIEIRA, D.M.S. Resistência à penetração em área de pastagem de capim tifton, influenciada pelo pisoteio e irrigação. Bioscience Journal, Uberlândia, v.28, Supplement 1, p.232-239, 2012

TREIN, C.R.; COGO, N.P.; LEVIEN, R. Métodos de preparo do solo na cultura do milho e ressemeadura do trevo, na rotação aveia+trevo/ milho, após pastejo intensivo. Revista Brasileira de Ciência do Solo, Campinas, v.15, n.1, p.105111, 1991.

VILELA, L.; MARTHA JUNIOR, G.B.; MACEDO, M.C.M.; MARCHÃO, R.L.; GUIMARÃES JÚNIOR, R.; PULROLNIK, K.; MACIEL, G.A. Sistemas de integração lavoura-pecuária na região do Cerrado. Pesquisa Agropecuária Brasileira, Brasília, v.46, n.10, p.1127-1138, 2011. 